\title{
STRUCTURAL EQUATION MODEL (SEM) FOR PREDICTING CAUSING FACTORS ON JOB STRESS IN INFORMATION TECHNOLOGY (IT) INDUSTRYOF CHENNAI CITY
}

\author{
Dr.T.Narayana Reddy ${ }^{1}$ \\ Associate Professor, \\ Department of Management Studies, \\ JNTUA Ananthapuramu, \\ e-mail: tnreddyjntua@gmail.com \\ Dr. S. Mohana ${ }^{2}$ \\ Associate Professor, \\ Department of Management Studies, \\ Sri Sai Institute of Technology and Science, Rayachoty, \\ e-mail: smohanyadav2012@gmail.com.
}

\begin{abstract}
This research was conducted to investigate causing factors (work to family conflict, family to work conflict, work support, family support stress and factors) affect job stress of IT professionals. The data of this study was quantitative collected through questionnaire from 256 respondents from different IT companies of Chennai city. The results of the current study reveal that there is a significant positive relationship between causing factors with job stress. The study also discusses the recommendation for future research.
\end{abstract}

Key words: Work to Family Conflict, Family to Work Conflict, Work Support,
Family Support Stress Factors, Job Stress and Chennai city.

\section{Introduction}

Life is like riding a bicycle; to keep our balance we must keep moving\| saidthe great scientist Albert Einstein. While riding a bicycle if there is an imbalance andif the rider is unable to control he may fall down. This is true in the case of all theemployees who are struggling with work-life balance issues in their livelihood. Overthe past few decades, a dramatic change had occurred in the labor market anddemographic profiles of employees. Families shifted from the traditional malebreadwinner 'role to dualearner couples and single parent families. 
Relative to theworking environment, organizations are demanding an increase in employeeflexibility and productivity. The traditional-job for lifell has changed into aneconomic environment of instability and job uncertainty. Workers' perspectives andexpectations have also changed towards work. New orientations towards lifelonglearning, personal and career development, and an increased awareness and need for abalance between work and life have affected organizations through incentivizing theintroduction of policies such as flexible working, leave amenities and wellnessprograms etc. As a result of these demographic, employment and organizationaltrends, both men and women have experienced an increase in demands from thefamily and work domains.

\section{Literature Review}

Fisher-McAuley et al. (2003) examined the relation between employees'beliefs about having a balance between work and personal life, and the feeling of job stress, job satisfaction, and reasons why one might quit his/her job. The data was collected from two independent, heterogeneous samples of employees. The first sample comprised of 603 fitness professionals while the second consisted of 545 managers employed in a variety of organizations spanning many industries and functional departments. The findings indicated that having a lack of work/life balance was an occupational stressor that leads to strains, including feeling of overall work strain, job dissatisfaction, non-work related reasons for leaving and turnover intentions. [1]

Komal saeed etal. (2014) conducted a study to investigate the relationshipbetween work life balances, job stress and job satisfaction among university teachers.A sample of 171 has been taken as random sampling. The results show that asignificant and positive correlation exists between work life balance and jobsatisfaction. And also relationship between work life balance and job satisfaction isfound significant and of moderate positive nature which mean increase in work life balance will results in increase in job satisfaction. [2]

Onur Balkan (2014) conducted a study to know the effects of work lifebalance on job stress and individual performance. A sample of 232 postgraduate anddoctoral students was selected for the study. The survey consisted of three measures.In the first part questions about the work-life conflict; in the other two parts questionsdesigned to measure job stress and performance were asked. The results of the 
studyrevealed that there is strong relation between job stress and work life balance that isbecause of wok family conflicts. [3]

Sheena Johnson et al (2005) in their study the experience of work-relatedstress across occupations made an attempt to compare occupational stress amongdiverse set of occupations. 26 occupations were selected for the study and the threevariables namely psychological well-being, physical health and job satisfaction aremeasured and compared. Out of 26 occupations, call centers, prison officers, police,teachers, customer services, social services employees are having worse than averagescores on each of the three factors and reported as the most stressful occupationsregarding physical and psychological well-being and as having the lowest levels of job satisfaction. [4]

Coetzer and Rothmann (2006) conducted a study to identify occupationalstressors for employees in an insurance company and to assess the relationshipsbetween occupational stress, ill health and organizational commitment. A cross-sectionalsurvey design was used with a sample of 613 employees in an insurancecompany. An Organizational Stress Screening Tool (ASSET) was used as measuringinstrument. The results showed that job insecurity as well as pay and benefits were thehighest stressors in the insurance industry. Two stressors, namely job characteristicsand control were statistically significant predictors of low organizational commitment. Physical ill health was best predicted by overload and job characteristics. Threestressors, namely work-life balance, overload and job characteristics best predictedpsychological ill health. [5]

Aniza et al. (2010) conducted a cross-sectional study on organizational factorsthat influences job stress among Medical Laboratory Technologists (MLT) in KlangValley's Hospitals. Three organizational factors that were measured in the study areinterpersonal factor, job condition and career development. A total of 249 respondentsparticipated in this study, 126 were from the private hospitals and 123 from the government hospitals. The study found prevalence of stress was higher in the privatehospitals compared to the government hospitals. Further found all the threeorganizational factors were significantly associated with job stress. [6]

Aamir sarwar (2013) in their study found that level of stress is same for bothmen and women. When compare to manufacturing and services sectors services sectorhave more stress. The dimensions of work holism, work values and job demands thatemerged as predictors of stress and 
anxiety Work stress has significant impact on anindividual employee and family. [7]

Ejaz Ahmed Khan et al (2014) in their study Impact of Job Stress on Job Attitudesand Life Satisfaction in College Lecturers\|, aimed to find out the relationship of jobstress with job attitudes in college lecturers. Total of 140 respondents were selectedfor the study. And they found that there is a negative relationship of job stress withjob performance, job satisfaction and that the level of stress and turnover intentions inunmarried lecturers is high as compare to married lecturers. [8]

\section{Rajeswari and Anatharaman} (2003) examined causes of negative pressure among software professionals, from the perspective of the software development process. A multiple response questionnaire was developed to measure sources of pressure among software professionals, based on a series of interactions with academicians, software professionals and senior software professionals employed in software industry. Ten key factors that cause stress in software professionals are identified using exploratory factor analysis from 156 usable responses. These ten factors are found to explain nearly two-thirds of the variance. The results indicate that stress resulting from fear of obsolescence and individual team interactions account for maximum variance. The results reveal that the stress levels are not high, among the respondents of the current study. [9]

A study conducted by Chaturvedi, Kalyanasundaram, Jagadish, Prabhu and Narasimha (2007) on IT/ITeS professionals in Bangalore to detect stress,anxiety and depression showed that $36 \%$ of the sample could be considered asprobable psychiatric cases. Common problems noted were the feeling of beingconstantly under strain; the inability to enjoy daily activities; being edgy, bad-temperedand dissatisfied with work tasks assigned; and not feeling in good health.The authors found that the rate of psychiatric morbidity in the sample was higher thanthat reported for the general population in India. [10]

In Japan, Tominaga, Asakura and Akiyama (2007) conducted a survey on1,000 IT employees distributed across 53 companies and showed that the chiefstressors were work overload, career and future ambiguity, inadequate performanceappraisal systems and poor supervisor support.[11]

Vimala and Madhavi (2009) explored the influence of age and experience onstress and depression and the relationship between stress and depression amongwomen information technology (IT) professionals in Chennai, India. The study wasconducted in 
Chennai, India with a sample of 500 women IT professionals. Thesample selection was done by a convenience sampling method. The data collectedwere analyzed using descriptive one-way analysis of variance and Pearson correlation test. Results showed that the women IT professionals experience moderatelevel of overall stress and stress dimensions. This study also reveals that $84 \%$ of the respondents' experience medium level of depression and also suggest that age andexperience significantly influence the overall stress and depression experienced by theemployees. The study found a strong relationship between overall stress anddepression.[12]

Dr. A. Chandra Mohan et al (2010)in their study -An Empirical Study onStress Levels among Software Professionals\| found that employees with high andmedium self-esteem experience high level of stress. A total of 300 softwareemployees were taken for the study with the objective to know the level of stressexperience by the software employees. Long working hours, work pressure, erraticfood intervals, anxiety were found to be the reasons affecting personal health. Marriedemployees comparatively experience high stress than unmarried. [13]

Dr.C. Madhavi (2011) studied the relationship between work family issueand the role stress dimensions among 485 women software professionals and foundthat there is association between work family issues and demographic factors. Tenorganizational role stress dimensions like inter-role distance, role stagnation, roleexpectation conflict, role erosion, role overload, role isolation, personal inadequacy,self-role distance, role ambiguity, resource inadequacy were taken to find out therelationship between work life issues and stress dimensions. Finally, she concluded that stress and work life issues prevail among dual career women. The role dimensions experienced by the women software professionals make a significant impact upon their work family issues. [14]

L. Ranjit (2012), in his study job stress and quality of life of women software employees found that all demographic factors like age, marital status, educational qualification, designation, monthly income and hours of work do influence the quality of life of the respondents and the level of job stress influence the level of quality of life. Stress has touched almost all professions and is high in software profession because of their nature of work, target, achievements, and night shift and over work load. From the 201 women respondents he concluded that the higher the level of stress 
lower is the quality of life and vice versa. [15]

T. Thirumaleswari (2013) conducted a study on job stress among software employees and relaxation techniques. 100 respondents were randomly chosen for the study. And they found that the level of stress and its amount of consequences vary within and between organizations based on the nature and type of work practices. [16]

Prasad, K. D. V et. al.(2015)concluded that the occupational stress is having moderate impact on the employees' performance of the institute, the job related stress in general and the stress factor job security in particular. The employees' reaction to the stress physiological factors also has moderate effect the performance of an employee. Health-wise, some employees had developed chronic neck and back pain, an effect of long sitting hours at work. [17]

\section{Gap of the Research}

Researchers have predominantly focused on either work-life balance issues or occupational stress faced by IT professionals in India and very scant work has been done in the area of work-life balance along with job stress of software professionals. The divide of demographic variables with respect to work life balance and job stress is not much studied and there are many unanswered questions.

\section{Research Problem}

Responding to questions on work life balance and stress is difficult as the respondents have to thinkand deliberate to know and assess for themselves the extent and underlying aspects of work life balance and stress. Further, provision of sufficient time for the respondents for their honest answers is always a challenge as each time; some of their responses may vary to certain aspects.It required a thorough revision of the wording, sequence and classification of the questions in the questionnaire. Efforts were put in to sincerely gather the truthful and uncontrived data from the respondents that ensure the results to be reliable and pragmatic.

\section{Research Objectives}

1. To identify the factors causing on job stress ofIT professionals.

2. To measure the impact of causingfactors on job stress of IT professionals.

3.

\section{Research Hypothesis}


H0: There is no significant relationship between causing factors and job stress of IT professionals.

- $\mathrm{H}_{01}$ : There is no significant relationship between work to family conflict and job stress.

- $\mathrm{H}_{02}$ : There is no significant relationship between family to work conflict and job stress.

- $\mathrm{H}_{03}$ : There is no significant relationship between work to work support and job stress.

- $\mathrm{H}_{04}$ : There is no significant relationship between work to family support and job stress.

- $\mathrm{H}_{05}$ : There is no significant relationship between work to stress factors and job stress.

\section{Methodology adopted for Research}

\section{Data Sources}

The study is based on primary data and secondary data. Primary data is collected through a well-framed and structured questionnaire to elicit the wellconsidered opinions of the respondents. Based on the in-depth study of literature the questionnaire for the study is prepared. From the extensive literature survey the information is divided into two parts. Workfamily conflicts and supports, Job stress variables. Most of the responses are measured with the help of 5 point Likert scale fromstrongly disagree to strongly agree. Direct interviews and discussions are also conducted with respondents to get basic inputs.The secondary data is collected from business periodicals, business journals, magazines, publications, reports, research articles, websites, manuals and booklets.

\section{Sampling Procedure for Research}

The study is proposed to be conducted among software professionals in IT industry of Chennai City. The study adopts stratified convenience sampling to collect the responses of the software professionals in Chennai City. The questionnaire is distributed personally to the software professionals and the soft copy also is floated to all the contacts of software professionals in turn.Software Professionals who have been full time employees with at least 6 months of work experience in the selected IT companies were taken as sample.700 questionnaires were mailed to software professionals and received 360 filled questionnaires. Out of 360 questionnaires 256 were useful with full information in all aspects. Hence the sample size of this study is 256 employees.

\section{Statistical Tools for Analysis}

All the survey responses were coded into Microsoft Excel2010 spreadsheet, 
verifying for missing data and inconsistently filled-in questionnaires. The data coded were transferred to SPSS and analyzed employing reliability analysis, defined variables and, all sorts of descriptive statistics of the responses were calculated. Testing the hypotheses was done, using

SPSS and Structural Equation Model (SEM).

The following statistical tools were used for data analysis:

- Reliability \& Validity Test

- Confirmatory Factor Analysis

- Multiple Linear Regression

\section{Data Analysis \& Results}

\section{Reliability and Validity Test}

Table.1: Case Processing Summary

\begin{tabular}{|ll|c|c|}
\hline & & N & \% \\
\hline \multirow{3}{*}{ Cases } & Valid & 256 & 100.0 \\
& Excluded $^{\mathrm{a}}$ & 0 & .0 \\
& Total & 256 & 100.0 \\
\hline
\end{tabular}

a. Listwise deletion based on all variables in the procedure.

Table.2: Reliability Statistics

\begin{tabular}{|c|c|}
\hline Cronbach's Alpha & N of Items \\
\hline .891 & 19 \\
\hline
\end{tabular}

The internal consistency of the questionnaire of 19 questions with a value of the Cronbach's Alpha is 0.891 , which shows that data is 89.1 per cent reliable and valid.

\section{AMOS output of the measurement model or CFA -Standardized}




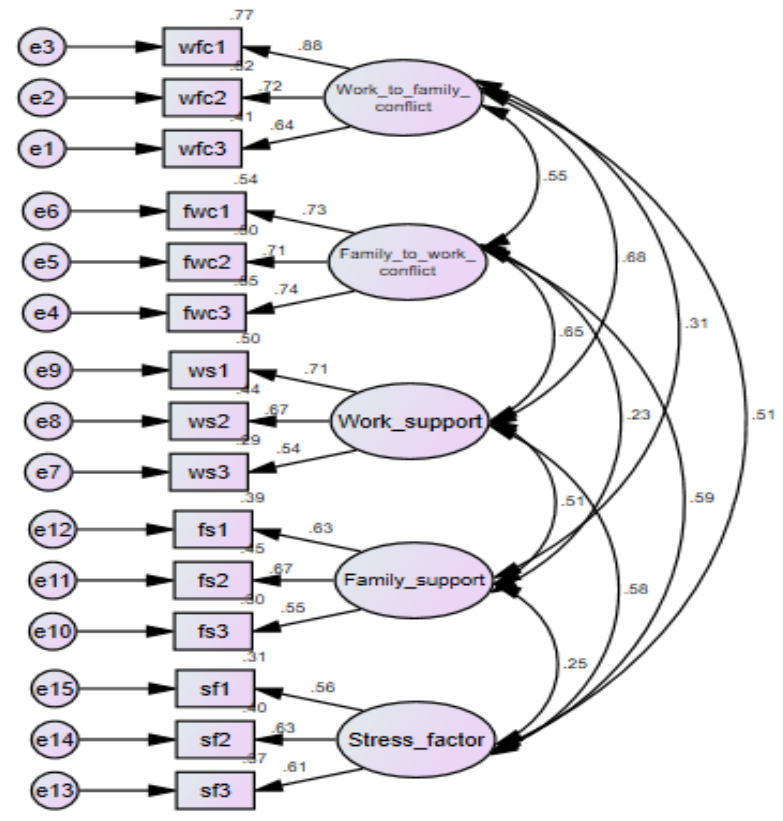

Figure: 1. AMOS output of the measurement model or CFA -Standardized

Table.3: Regression Weights: (Group number 1 - Default model)

\begin{tabular}{|l|l|l|r|r|r|r|r|}
\hline & & & Estimate & S.E. & C.R. & P & Label \\
\hline wfc3 & $<---$ & Work to family conflict & 1.000 & & & & \\
\hline wfc2 & $<---$ & Work to family conflict & 1.062 & .080 & 13.219 & $* * *$ & \\
\hline wfc1 & $<---$ & Work to family conflict & 1.396 & .099 & 14.117 & $* * *$ & \\
\hline fwc3 & $<---$ & Family to work conflict & 1.000 & & & & \\
\hline fwc2 & $<---$ & Family to work conflict & .926 & .068 & 13.582 & $* * *$ & \\
\hline fwc1 & $<---$ & Family to work conflict & 1.013 & .073 & 13.919 & $* * *$ & \\
\hline ws3 & $<---$ & Work support & 1.000 & & & & \\
\hline ws2 & $<---$ & Work support & 1.261 & .126 & 10.039 & $* * *$ & \\
\hline ws1 & $<---$ & Work support & 1.387 & .134 & 10.325 & $* * *$ & \\
\hline fs3 & $<---$ & Family support & 1.000 & & & & \\
\hline fs2 & $<---$ & Family support & 1.229 & .149 & 8.273 & $* * *$ & \\
\hline fs1 & $<---$ & Family support & 1.103 & .134 & 8.254 & $* * *$ & \\
\hline sf3 & $<---$ & Stress factor & 1.000 & & & & \\
\hline sf2 & $<---$ & Stress factor & .995 & .110 & 9.088 & $* * *$ & \\
\hline sf1 & $<---$ & Stress factor & .935 & .109 & 8.592 & $* * *$ & \\
\hline
\end{tabular}

Table.4: Standardized Regression Weights: (Group number 1 - Default model) 


\begin{tabular}{|l|l|l|r|}
\hline & & & Estimate \\
\hline wfc3 & $<---$ & Work to family conflict & .639 \\
\hline wfc2 & $<---$ & Work to family conflict & .722 \\
\hline wfc1 & $<---$ & Work to family conflict & .877 \\
\hline fwc3 & $<---$ & Family to work conflict & .739 \\
\hline fwc2 & $<---$ & Family to work conflict & .707 \\
\hline fwc1 & $<---$ & Family to work conflict & .735 \\
\hline ws3 & $<---$ & Work support & .542 \\
\hline ws2 & $<---$ & Work support & .666 \\
\hline ws1 & $<---$ & Work support & .709 \\
\hline fs3 & $<---$ & Family support & .547 \\
\hline fs2 & $<---$ & Family support & .668 \\
\hline fs1 & $<---$ & Family support & .627 \\
\hline sf3 & $<---$ & Stress factor & .612 \\
\hline sf2 & $<---$ & Stress factor & .630 \\
\hline sf1 & $<---$ & Stress factor & .557 \\
\hline
\end{tabular}

Table.5: Intercepts: (Group number 1 - Default model)

\begin{tabular}{|l|l|l|l|l|l|}
\hline & Estimate & S.E. & C.R. & P & Label \\
\hline wfc3 & 3.118 & .061 & 51.439 & $* * *$ & \\
\hline wfc2 & 3.039 & .057 & 53.336 & $* * *$ & \\
\hline wfc1 & 2.577 & .062 & 41.793 & $* * *$ & \\
\hline fwc3 & 3.326 & .061 & 54.711 & $* * *$ & \\
\hline fwc2 & 3.384 & .059 & 57.534 & $* * *$ & \\
\hline fwc1 & 3.178 & .062 & 51.296 & $* * *$ & \\
\hline ws3 & 3.135 & .059 & 52.735 & $* * *$ & \\
\hline ws2 & 3.172 & .061 & 51.914 & $* * *$ & \\
\hline
\end{tabular}




\begin{tabular}{|l|l|l|l|l|l|}
\hline & Estimate & S.E. & C.R. & P & Label \\
\hline ws1 & 3.220 & .063 & 51.017 & $* * *$ & \\
\hline fs3 & 3.183 & .060 & 53.182 & $* * *$ & \\
\hline fs2 & 3.228 & .060 & 53.547 & $* * *$ & \\
\hline fs1 & 3.164 & .058 & 54.916 & $* * *$ & \\
\hline sf3 & 3.131 & .060 & 51.840 & $* * *$ & \\
\hline sf2 & 3.234 & .058 & 55.389 & $* * *$ & \\
\hline sf1 & 3.054 & .062 & 49.139 & $* * *$ & \\
\hline
\end{tabular}

Table.6: Covariance's: (Group number 1 - Default model)

\begin{tabular}{|l|c|l|r|r|r|r|l|}
\hline & & & Estimate & S.E. & C.R. & P & Label \\
\hline $\begin{array}{l}\text { Work to family } \\
\text { conflict }\end{array}$ & $<-->$ & Family to work conflict & .497 & .064 & 7.739 & $* * *$ & \\
\hline $\begin{array}{l}\text { Family to work } \\
\text { conflict }\end{array}$ & $<-->$ & Work support & .488 & .064 & 7.587 & $* * *$ & \\
\hline Work support & $<-->$ & Family support & .278 & .049 & 5.728 & $* * *$ & \\
\hline Stress factor & $<-->$ & Family support & .155 & .046 & 3.346 & $* * *$ & \\
\hline $\begin{array}{l}\text { Work to family } \\
\text { conflict }\end{array}$ & $<-->$ & Work support & .441 & .059 & 7.519 & $* * *$ & \\
\hline $\begin{array}{l}\text { Work to family } \\
\text { conflict }\end{array}$ & $<-->$ & Family support & .203 & .045 & 4.514 & $* * *$ & \\
\hline Stress factor & $<-->$ & Work to family conflict & .375 & .058 & 6.512 & $* * *$ & \\
\hline $\begin{array}{l}\text { Family to work } \\
\text { conflict }\end{array}$ & $<-->$ & Family support & .171 & .050 & 3.411 & $* * *$ & \\
\hline Stress factor & $<-->$ & Family to work conflict & .506 & .070 & 7.252 & $* * * *$ & \\
\hline Stress factor & $<-->$ & Work support & .359 & .056 & 6.412 & $* * *$ & \\
\hline
\end{tabular}

Table.7: Correlations: (Group number 1 - Default model)

\begin{tabular}{|l|l|l|l|}
\hline & & & Estimate \\
\hline Work_to_family_conflict & $<-->$ & Family_to_work_conflict & .553 \\
\hline Family_to_work_conflict & $<-->$ & Work_support & .652 \\
\hline
\end{tabular}




\begin{tabular}{|l|l|l|l|}
\hline & & & Estimate \\
\hline Work_support & $<-->$ & Family_support & .509 \\
\hline Stress_factor & $<-->$ & Family_support & .248 \\
\hline Work_to_family_conflict & $<-->$ & Work_support & .684 \\
\hline Work_to_family_conflict & $<-->$ & Family_support & .309 \\
\hline Stress_factor & $<-->$ & Work_to_family_conflict & .506 \\
\hline Family_to_work_conflict & $<-->$ & Family_support & .225 \\
\hline Stress_factor & $<-->$ & Family_to_work_conflict & .589 \\
\hline Stress_factor & $<-->$ & Work_support & .582 \\
\hline
\end{tabular}

Table.8: Variances: (Group number 1 - Default model)

\begin{tabular}{|l|l|l|l|l|l|}
\hline & Estimate & S.E. & C.R. & P & Label \\
\hline Work to family conflict & .775 & .103 & 7.490 & $* * *$ & \\
\hline Family to work conflict & 1.043 & .120 & 8.684 & $* * *$ & \\
\hline Work support & .537 & .091 & 5.889 & $* * *$ & \\
\hline Family support & .555 & .104 & 5.337 & $* * *$ & \\
\hline Stress factor & .707 & .115 & 6.148 & $* * *$ & \\
\hline e1 & 1.124 & .081 & 13.910 & $* * *$ & \\
\hline e2 & .804 & .065 & 12.386 & $* * *$ & \\
\hline e3 & .455 & .073 & 6.278 & $* * *$ & \\
\hline e4 & .868 & .078 & 11.087 & $* * *$ & \\
\hline e5 & .895 & .075 & 11.949 & $* * *$ & \\
\hline e6 & .913 & .081 & 11.206 & $* * *$ & \\
\hline e7 & 1.290 & .091 & 14.173 & $* * *$ & \\
\hline e8 & 1.075 & .087 & 12.322 & $* * *$ & \\
\hline e9 & 1.026 & .091 & 11.228 & $* * *$ & \\
\hline e10 & 1.297 & .103 & 12.624 & $* * *$ & \\
\hline e11 & 1.041 & .110 & 9.460 & $* * *$ & \\
\hline
\end{tabular}




\begin{tabular}{|l|l|l|l|l|l|}
\hline & Estimate & S.E. & C.R. & P & Label \\
\hline e12 & 1.041 & .098 & 10.670 & $* * *$ & \\
\hline e13 & 1.179 & .101 & 11.664 & $* * *$ & \\
\hline e14 & 1.062 & .095 & 11.215 & $* * *$ & \\
\hline e15 & 1.378 & .108 & 12.808 & $* * *$ & \\
\hline
\end{tabular}

Table.9: Squared Multiple Correlations: (Group number 1 - Default model)

\begin{tabular}{|l|l|}
\hline & Estimate \\
\hline sf1 & \\
\hline sf2 & .310 \\
\hline sf3 & .397 \\
\hline fs1 & .375 \\
\hline fs2 & .394 \\
\hline fs3 & .446 \\
\hline ws1 & .300 \\
\hline ws2 & .502 \\
\hline ws3 & .443 \\
\hline fwc1 & .294 \\
\hline fwc2 & .540 \\
\hline fwc3 & .500 \\
\hline wfc1 & .546 \\
\hline wfc2 & .768 \\
\hline wfc3 & .521 \\
\hline SEM Path & .408 \\
\hline
\end{tabular}

SEM Path

After complying with Reliability and Validity checks using Confirmatory Factor Analysis (CFA), estimation of overall Model fit was done using structural equation modelling. First, we need to construct the SEM path diagram based on the theoretical frame work. The structural model path diagram is shown in figure 1 is a graphical representation of the mathematical equation
(Byrne, 2010) [17]. It shows how the independent and dependent constructs are interrelated with each other in a structured mathematical manner. The one-way arrow which starts from the exogenous variable and ends to the endogenous denotes the regression weight. We can understand the level of impact of the exogenous variable on an endogenous variable by its unstandardized and standardized regression 
coefficients. The two-way arrow denotes the covariance or correlation.

Totally there are 15 observed variables which are referred as predictors as it predicts the constructs or latent variables and there are totally 1 unobserved variable which can also be referred as latent variables or constructs as it is conceptually related with the observed variables. The exogenous Variables- Work to Family Conflict, Family to Work Conflict, Work Support, Family Support and Stress Factors affects the endogenous variable -Job Stress, in turn, affect the endogenous Variable-Employee
Retention. Each and every observed variable have an error term and it is denoted with e1 to e15. Few latent variables like Work to Family Conflict, Family to Work Conflict, Work Support, Family Support and Stress Factors are inter correlated by drawing the covariance curves in the model.

Once the structural equation model is drawn using AMOS, the sample data is imported from SPSS and we need to run the model. If the data meets all the assumptions of SEM as discussed in the previous topics, then we shall get the output without any error in both graphical and tabulated form.

\section{Structural Model Path Analysis}

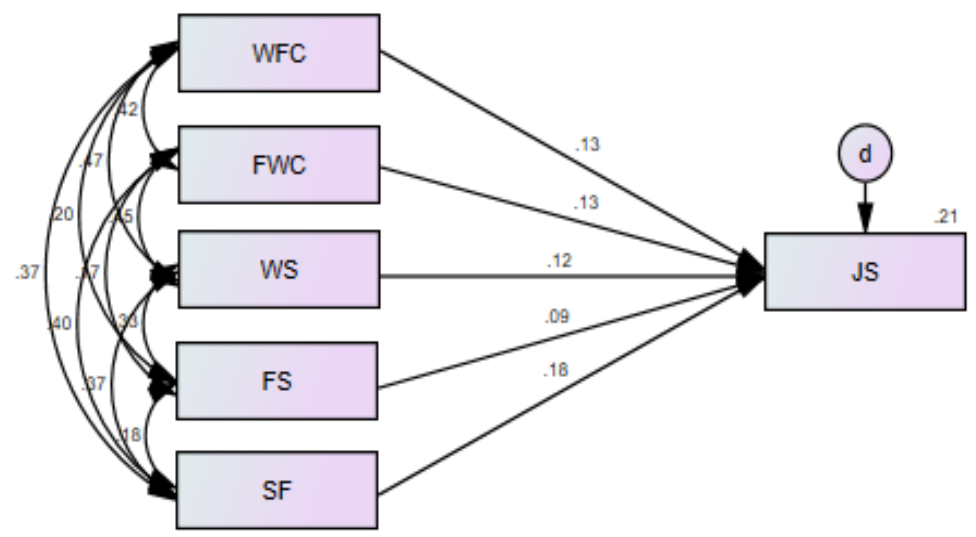

Figure: 2. Structural Model Path Analysis

\section{Structural Model Fit Estimation}

Figure 2 indicates the standardized path regression coefficients and the relationship between unobserved and observed variables with respect to the path diagram.

Table.10:Structural Model Fit Estimation

\begin{tabular}{|l|c|c|}
\hline Indices & Recommended Value & Model Fit Indices \\
\hline CMIN/df & $<3$ & 2.163 \\
\hline
\end{tabular}




\begin{tabular}{|l|c|c|}
\hline $\mathrm{p}$-value & $\geq 0.05$ & .000 \\
\hline GFI & $\geq 0.90$ & 0.900 \\
\hline AGFI & $\geq 0.80$ & 0.968 \\
\hline NFI & $\geq 0.90$ & 1.000 \\
\hline CFI & $\geq 0.90$ & 1.000 \\
\hline RMSEA & $\leq 0.08$ & .016 \\
\hline P Close & $\geq 0.05$ & .000 \\
\hline
\end{tabular}

The structural model fit is checked based on CMIN/df, p-value, Goodness of Fit (GFI), Adjusted Goodness of Fit (AGFI), NFI, Comparative Fit Index (CFI), Root Mean square of approximation (RMSEA) and P Close. The Model fit indices for the constructs have been found and the summary of the result is shown in the above table where the obtained Model fit indices are compared with the recommended value. The detailed AMOS output is given above tables. We have not considered the actual chi square value as the chances of model rejection will be high when the sample size increases. Hence we have divided the chi square value with the degrees of freedom so that we can overcome the sample size issue. The result of chi square value divided by the degrees of freedom is shown in the table as 2.163 which is below than the acceptable limit 3 . The obtained p-value is 0.05 which is equal to the recommended value. The obtained GFI value is 1.000 which is equal to the recommended value of 0.9 . The obtained AGFI value is 0.968 which is above the recommended value of 0.8 . The obtained NFI value is 1.000 which is greater than the recommended value of 0.90 . The obtained CFI value is 1.000 which is greater than the recommended value of 0.90 . The obtained RMSEA value is 0.016 which is lesser than the recommended value of 0.08 . The obtained P-close value is 0.00 which is less to the recommended value of 0.05 . Hence we can find the overall model fit indices are within the acceptable recommended values as proposed by the researchers, so we can conclude that the hypothesized model fits with the sample data. All the five parameters have met all the other recommended value to verify fitness of the Model. Hence we can conclude that the Model is perfectly fit.

\section{Testing Structural Relationships}

To know whether the hypothesized paths are significant or not, the standardized regression weights of the output of the hypothesis path are compared against the p- 
value. The table below shows the relationship between Independent and dependent variables with respect to Hypothesis. By referring to the $\mathrm{P}$ value, each and every hypothesis has been specified whether it is significant or not significant. The result shows that the hypothesized model fits with the obtained sample data.

The summary and interpretation of the result are given below:

\section{Work to family conflict}

The probability of getting a critical ratio as large as 2.844 in absolute value is .004. In other words, the regression weight for Work to family conflict(WFC) in the prediction of job stress (JS) is significantly different from zero at the 0.01 level (twotailed).

\section{Family to work conflict}

The probability of getting a critical ratio as large as 2.719 in absolute value is .007. In other words, the regression weight for Family to work conflict(FWC) in the prediction of job stress (JS) is significantly different from zero at the 0.01 level (twotailed).

\section{Work Support}

The probability of getting a critical ratio as large as 2.529 in absolute value is .011. In other words, the regression weight for Work Support (WS) in the prediction of Job Stress (JS) is significantly different from zero at the 0.05 level (two-tailed).

\section{Family Support}

The probability of getting a critical ratio as large as 2.131 in absolute value is .033. In other words, the regression weight for Family Support (FS) in the prediction of Job Stress (JS) is significantly different from zero at the 0.05 level (two-tailed).

\section{Stress Factors}

The probability of getting a critical ratio as large as 4.125 in absolute value is less than 0.001. In other words, the regression weight for Stress Factors (SF) in the prediction of Job Stress (JS) is significantly different from zero at the 0.001 level (two-tailed).

\section{Table.11:Estimated Standardized regression of the hypothesis}

\begin{tabular}{|c|l|c|c|c|}
\hline $\begin{array}{c}\text { S. } \\
\text { No. }\end{array}$ & \multicolumn{1}{|c|}{ Hypothesis } & $\begin{array}{c}\text { Standardized } \\
\text { Regression } \\
\text { Weights }\end{array}$ & $\mathbf{P}$ & $\begin{array}{c}\text { Significant/Not } \\
\text { Significant }\end{array}$ \\
\hline $\mathrm{H}_{01}$ & $\begin{array}{l}\text { There is no significant relationship } \\
\text { between work to family conflict and job } \\
\text { stress. }\end{array}$ & 0.133 & 0.004 & Significant \\
\hline $\mathrm{H}_{02}$ & There is no significant relationship & 0.127 & 0.007 & Significant \\
\hline
\end{tabular}




\begin{tabular}{|c|l|c|c|c|}
\hline & $\begin{array}{l}\text { between family to work conflict and job } \\
\text { stress. }\end{array}$ & & & \\
\hline $\mathrm{H}_{03}$ & $\begin{array}{l}\text { There is no significant relationship } \\
\text { between work support and job stress. }\end{array}$ & 0.123 & 0.011 & Significant \\
\hline $\mathrm{H}_{04}$ & $\begin{array}{l}\text { There is no significant relationship } \\
\text { between family support and job stress. }\end{array}$ & 0.089 & 0.033 & Significant \\
\hline $\mathrm{H}_{05}$ & $\begin{array}{l}\text { There is no significant relationship } \\
\text { between stress factors and job stress. }\end{array}$ & 0.184 & 0.000 & Significant \\
\hline
\end{tabular}

\section{Suggestions}

The present study proposes a model of the impact of causing factors on the job stress. The study found that work to family conflict, family to work conflict, work support, family support and stress factors are impacting significantly the job stress. Therefore, IT Companies HR managers should focus on the above factors to reduce job stress of IT professionals.

\section{Conclusion}

The study investigated the impact of causing factors on job stress of IT professionals, concluded that work to family conflicthad the highest impact on the job stress of the IT professionals followed by family to work conflict, work support, family support and stress factors.

\section{Recommendation for further research}

This research study has substantial scope for extension in terms of depth as well as

\section{References}

1. Fisher-McAuley et.al., Modeling the relationship between work life balance and organizational breadth. Hence such areas are presented below:

- The present study confines itself to IT companies only and does not cover other industries. Thus the further study may be undertaken on other industries to identify relevant determinants.

- The study focused on the causing factors and job stress of the IT professionals. Further research may be conducted on the job stress and job performance other industry.

- Further research is recommended by carrying out a comparative study among the south Indian cities because the residents in other parts of the country may have different causing factors and job stress in respect of IT industry.

outcomes, Paper presented at the Annual conference of the Society for Industrial-Organizational Psychology. Orlando, (2003), 1-26. 
2. Komal saeed et al., Examining the relationship between work life balance, jobstress and job satisfaction among university teachers. International journal ofmultidisciplinary sciences and engineering, 5(6), (2014), 9-15.

3. Onur Balkan, Work-Life Balance, Job Stress and Individual Performance: AnApplication International Journal of Management Sciences and BusinessResearch, 3(3), (2014), 38-46.

4. Sheena Johnson et al., "The experience of work-related stress acrossoccupations" Journal of Managerial Psychology, 20(2), (2005), 178-187.

5. Coetzer, W.J., \& Rothmann, S, Occupational stress of employees in aninsurance company, South African Journal of Business Management, 37(3),(2006), 29-39.

6. Aniza, I. M. H.; Malini, R. M. \& Khalib, L. MPH, "A Study on OrganizationalFactors That Influence Job Stress Among Medical Laboratory Technologists inKlang Valley Hospitals", Med J Malaysia, 65(2), (2010), 103 - 107.

7. Aamir sarwar, Work Stress and Family Imbalance Comparative
Study ofManufacturing and Services Sector in Pakistan, Middle-East Journal ofScientific Research 16 (8), (2013), 51-61.

8. Ejaz Ahmed Khan et al., Impact of Job Stress on Job Attitudes and LifeSatisfaction in College Lecturers, International Journal of Information andEducation Technology, 4(3), (2014), 270-273.

9. Rajeswari, K.S. and Anantharaman. R, NSIGMIS, conference on Computerpersonnel research ${ }^{e e} 03$, Development of an Instrument to Measure Stress AmongSoftware Professionals Factor Analytic Study, (2003),34-43.

10. Chaturvedi SK, Kalyanasundaram S, Jagadish A, Prabhu V, Narasimha V.Detection of stress, anxiety and depression in IT/ITES professionals in theSilicon Valley of India: A preliminary study, Prim Care Comm Psychiatr, 12,(2007), 75-80.

11. Tominaga M, Asakura T, Akiyama $\mathrm{T}$, "The effect of micro and macro stressorsin the work environment on computer professionals' subjective health status andproductive behavior in Japan”, 45(3), (2007), 474-86.

12. Vimala. B and Madhavi. C, "A study on stress and depression experienced 
bywomen IT professionals in Chennai, India”, Psychology Research and BehaviorManagement, vol 2, (2009), 81-91.

13. Chandra Mohan et al., An Empirical Study On Stress Levels Among Software Professionals in The City of Chennai India, Abhinav National Monthly Refereed Journal of Research in Commerce \& Management, 2(5), (2010), 33-40.

14. Madavi.C, a study on work related stress and work family issues experiencedby women software professionals in Chennai, 3rd International Conference onInformation and Financial Engineering,12, (2011),264-268.

15. L.Ranjit, study on job stress and quality of life of women software employees,international journal of research in social sciences, 2(2), (2012), 276-291.

16. T. Thirumaleswari, A Study On Job Stress Among Employees of Software Industries in Chennai International Research Journal of Business andManagement, 3, (2013),1-6.

17. Byrne, B. M. (2010). Structural equation modeling with AMOS: basic concepts, applications, and programming (multivariate applications series). New York: Taylor \& Francis Group, 396, 7384.

18. Prasad, K. D. V., Vaidya, R., \& Anil Kumar, V. (2015). A study on causes of stress among the employees and its effect on the employee performance at the workplace in an International Agricultural Research Institute, Hyderabad, Telangana, India. International Journal of Management Research and Business Strategy, 4(4), 68-82. 